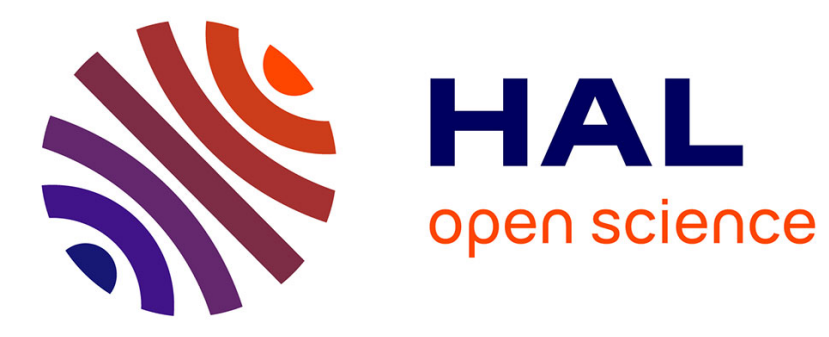

\title{
Managerial incentives and polluting Inputs under imperfect competition
}

Denis Claude, Mabel Tidball

\section{To cite this version:}

Denis Claude, Mabel Tidball. Managerial incentives and polluting Inputs under imperfect competition. Pierre-Olivier Pineau; Simon Sigué; Sihem Taboub. Games in Management Science., 280, Springer, pp.165-186, 2019, International Series in Operations Research \& Management Science, 978-3-03019106-1. 10.1007/978-3-030-19107-8_10. halshs-02283174

\section{HAL Id: halshs-02283174 \\ https://shs.hal.science/halshs-02283174}

Submitted on 11 Sep 2019

HAL is a multi-disciplinary open access archive for the deposit and dissemination of scientific research documents, whether they are published or not. The documents may come from teaching and research institutions in France or abroad, or from public or private research centers.
L'archive ouverte pluridisciplinaire HAL, est destinée au dépôt et à la diffusion de documents scientifiques de niveau recherche, publiés ou non, émanant des établissements d'enseignement et de recherche français ou étrangers, des laboratoires publics ou privés. 


\title{
Managerial incentives and polluting inputs under imperfect competition*
}

\author{
Denis Claude $^{(a)}$ and Mabel Tidball ${ }^{(b)}$
}

(a). LEDi, Université de Bourgogne-Franche Comté

(b). CEE-M, Université de Montpellier, Inra, Cnrs, SupAgro

\begin{abstract}
This paper explores the link between upstream input pricing and downstream strategic delegation decisions. It complements earlier contributions by studying how environmental emissions and tax payments alter the incentives business owners have to divert their managers from profit maximization in favor of sales revenue generation. Two scenarios are compared depending on whether the upstream supplier precommits to a fixed input price or adopts a flexible price strategy. Corresponding Subgame-Perfect Nash-Equilibria are characterized and elements of comparative statics analysis are presented. The analysis confirms that previous results - showing that a price precommitment makes the upstream supplier better off and downstream firms worse off - carry over to situations in which production generates pollution.
\end{abstract}

Keywords: precommitment, externality, delegation, vertical relations, managerial incentives

\section{Introduction}

This chapter bridges two fields of research in which Georges Zaccour has been active: the analysis of vertical relations and environmental and resource economics. The former studies relations between firms that intervene successively along the value chain whereas the latter deals with the relations between the economy and the environment. We can trace back his interest for vertical relations to his early contributions on the analysis of energy markets (Zaccour, 1983, 1987; Breton et al., 1990). Today this interest is mainly manifested in his work on marketing channels. ${ }^{1}$ But, it also comes up tangentially in a variety of contributions ranging from environmental economics - where sustainable tourism development may require tourism destinations to delegate expenditures in environmental remediation to a regional authority (Claude \& Zaccour, 2009) - to institutional economics - where good institutions are produced by the strategic precommitment of civil society to fight corruption (Ngendakuriyo \& Zaccour, 2013).

Strategies of "delegation" and "precommitment" are at the heart of the literature on strategic delegation to which this chapter contributes. ${ }^{2}$ Starting with Vickers (1985), Fershtman

\footnotetext{
${ }^{*}$ We would like to thanks the two anonymous referees for their useful comments and suggestions. This work was supported by the ANR GREEN-Econ research project (ANR-16-CE03-0005).

1 See Jorgensen \& Zaccour (2004) and the references therein.

${ }^{2}$ For literature surveys, see Lambertini (2017), Kopel \& Pezzino (2018) and Sengul et al. (2012).
} 
\& Judd (1987) and Sklivas (1987), this literature has examined the incentives owners have to delegate production decisions. By hiring a manager, the owner of a firm can credibly commit to pursue a goal that differs from maximizing profit. The managerial compensation contract will then be designed to convey the appropriate managerial incentives to guide the manager in his day-to-day decisions. Its terms will provide for a variable target-based bonus that rewards the manager's performance in achieving some alternative goal to (pure) profit maximization. This variable part may be based on any one or a combination of the following criteria : profit, sales volume or revenue, market share, and corporate social responsibilityor environmental objectives. Since rational managers respond to financial incentives conveyed by the variable part of their remuneration, they will be encouraged to deviate from profit maximization.

As is well known, by choosing to reward sales revenue rather than profit, the owner encourages the manager to adopt a more aggressive market behavior. Namely, the managerial firm will produce more (for any level of production of its competitors) than a profit-maximizing owner-managed firm. Financial disclosure rules usually ensure that the incentives embedded in managerial compensation contracts are common knowledge. ${ }^{3}$ Any change in the performance criteria presiding over managerial compensation will then affect the expectations of competing firms. This opens the door to a strategic manipulation of compensation contracts: each owner attempting to alter the expectations of rival firms to its own advantage.

But deviating from profit maximization is only profitable when the deviation is unilateral. And, since all owners face similar incentives to deviate, widespread deviations are to be expected and excessive output supply will result into lower profits for all. Hence, the opportunity to strategically delegate day-to-day production decisions to a manager closes as a trap on firm owners who actually find themselves confronted with a Prisoner's Dilemma.

Strategic delegation provides a much needed rationale for observed deviations from profit maximization. This rationale, however, assumes that firms are vertically integrated and produce their own inputs. When this assumption is relaxed, the vertical externality linked to input pricing appears to have a disciplining role on downstream firms' behavior. If duopolists buy in inputs from a common monopolist supplier, Park (2002) shows that strategic delegation becomes unprofitable for business owners. Wang \& Wang (2010) reach the same conclusion by assuming that managerial incentive contract rewards a combination of profit and market share (rather than profit and sale revenues). On the contrary, Liao $(2008$; 2010) shows that strategic delegation retains its strategic value if the input supplier precommits to a fixed input price. This conclusion is backed by Wang (2015), who proves it true when compensation contracts reward the manager's performance relative to peers. ${ }^{4}$ Finally, Claude (2018) shows that Park (2002)'s main results no longer holds if we consider a downstream market consisting of more than two - but a finite number of - firms.

This paper re-examines the link between vertical externalities and strategic delegation decisions. We consider an extended version of Park (2002)'s model in which downstream firms generate pollution emissions when they process the intermediate product into a final good. Specifically, we assume that the emission of a firm, per unit of output produced, is inversely related to that firm's productivity in processing inputs. Since pollution emissions are assumed to be taxed, downstream firms have an incentive to internalize them, at least in part.

Two papers have investigated the consequences of strategic delegation for environmental policy-making. In a Cournot duopoly with homogeneous goods and pollution emissions,

\footnotetext{
${ }^{3}$ See, Vural (2018) for the example of the ball bearing compagny SKF

4 This form of strategic delegation was first studied by Fumas (1992) and Miller \& Pazgal (2002)
} 
Barcena-Ruiz \& Garzon (2002) find that strategic delegation is profitable. At the equilibrium, managerial firms produce and emit more than profit-maximizing owner-managed firms. Consequently, the optimal environmental tax is higher than that required to regulate a standard Cournot market. Pal (2012) generalizes this result to differentiated industries. However, none of these papers has investigated how factor market imperfections alter managerial incentives in downstream markets, which is the main purpose of our paper. Since our model encompasses those of Park (2002) and Claude (2018), we check the robustness of their results.

The paper is organized as follows. Section 2 describes the model. Section 3 solves the managerial sub-game. Sections 4 and 5 characterize the sub game perfect Nash equilibrium (SPNE) depending on whether the upstream monopolist precommits to a price. SPNE outcomes are compared in Section 6. The last section concludes.

\section{The Model}

We extend the model of Park (2002) to account for the existence of pollution (or waste). Consider a vertical market structure with upstream monopoly and downstream quantity competition. The single upstream monopolist (indexed by up) produces at no cost a homogeneous input $x$ that it sells at a non-discriminatory price $k>0$. Let $x_{i}$ denote the input consumption of firm $i(i=1,2, \ldots, n)$ and $X=\sum_{i=1}^{n} x_{i}$ the aggregate input demand. The upstream supplier's profit function is simply $\pi_{\text {up }}=k X$.

Downstream firms rely on the same technology to turn the intermediate product $x$ into a final good $y$. Let $y_{i}$ denote the output of Firm $i(i=1,2, \ldots, n)$ and $Y=\sum_{i=1}^{n} y_{i}$ the aggregate downstream output. Firm $i$ 's production function is $y_{i}=\varepsilon x_{i}$, where $\varepsilon \in(0,1]$ is a parameter measuring Firm $i$ 's productivity.

Pollution emissions come as a by-product of production. More precisely, they are inversely related to Firm $i$ 's productivity and given by $e_{i}=(1-\varepsilon) x_{i}{ }^{5}$ We assume that the government levies a tax on pollution emissions at a rate $\tau \geq 0$. Obviously, the more inefficient the firm is (the lower the value of $\varepsilon$ ), the higher is the quantity of pollution emitted for each unit of the final good $y$ produced and the higher is the firm's tax bill for a given level of output. Conversely, if $\varepsilon$ is assumed equal to 1 then the firm no longer emits pollution and its environmental tax bill is zero. Without loss of generality, we assume that downstream firms face no other production cost than that associated with input purchase. Demand for the final good $y$ is represented by the inverse demand function $P(Y)=a-b Y$ with $a, b>0$. Under the above assumptions, Firm $i$ 's profit function is given by

$$
\pi_{i}=P(Y) y_{i}-k x_{i}-(1-\varepsilon) \tau x_{i} .
$$

Using the production function, the above can be expressed in terms of $y$ only:

$$
\pi_{i}=P(Y) y_{i}-A(k, \tau, \varepsilon) y_{i}, \quad \text { where } \quad A(k, \tau, \varepsilon)=\frac{k+\tau}{\varepsilon}-\tau,
$$

denotes firm i's effective marginal cost of production; namely, the sum of the firm's input expenditure $(k / \varepsilon)$ and environmental tax bill $(\tau(1-\varepsilon) / \varepsilon)$. Observe that $\partial A / \partial \varepsilon<0$,

\footnotetext{
${ }^{5}$ We assume that the more efficient the firm is, the less input is used per unit of output and thus the lower the level of waste or emission generated. This assumption conforms to empirical findings by Shadbegian \& Gray (2003). Examining the determinants of environmental performance at paper mills, they found that high productivity plants pollute less. More precisely, a $10 \%$ higher productivity level is associated with a $2.5 \%$ lower emission per unit of output. Furthermore, they found that unexpectedly high productivity levels are associated with unexpectedly low levels of emissions per unit of output. Shadbegian \& Gray (2003) advance two main explanations for their results. On the one hand, newer production plants may be more efficient in production but also designed so as to reduce pollution emissions or waste. On the other hand, older, more inefficient, firms may face less regulatory pressure and retrofitting their facilities may be extremely difficult so that abatement possibilities are reduced.
} 
$\partial A / \partial \tau>0$ and $\partial A / \partial k>0$, which is in accordance with intuition. Indeed, an increase in the price of factors ( $\tau$ for emissions, and $k$ for the intermediate product) leads to a corresponding increase in marginal cost, whereas an increase in the productivity parameter $\varepsilon$ translates into a reduced (effective) marginal cost.

The owners of downstream firms may hire managers to run their firms on their behalf. The decision to hire a manager leads to the so-called divorce between ownership and control. Indeed, when management and control functions are divorced, agency problems arise if the manager's interests diverge from those of the owner (Sengul et al., 2012). In the remainder of this paper, we assume that all agency problems have been resolved ${ }^{6}$ to focus our attention on the strategic value of delegation decisions. Following Vickers (1985), Sklivas (1987) and Fershtman \& Judd (1987), we assume that owners hire managers in order to credibly commit their businesses to objectives that differ from profit maximization. Here, we assume that this objective is the maximization of a weighted sum of profits and sales revenue; i.e.,

$$
F_{i}=\alpha_{i} \pi_{i}+\left(1-\alpha_{i}\right)\left[P(Y) y_{i}\right] .
$$

The profit weight $\alpha_{i}$ is chosen strategically by the owner of firm $i$ in order to manipulate the anticipations of rival firms to its own advantage (i.e., in a profitable way). The corresponding departure from profit maximization is credible since the inclusion of a target-based bonus in managerial compensation contracts ensures that appropriate incentives are conveyed to managers. ${ }^{7}$ Depending on the value selected for $\alpha_{i}$, owners can encourage a wide range of behaviors. To see this, let us rewrite Equation (3) as:

$$
F_{i}=P(Y) y_{i}-\alpha_{i} A(k, \tau, \varepsilon) y_{i} .
$$

Then the performance measure has straightforward interpretation. By choosing $\alpha_{i}=1$, firm owners encourage pure profit maximization. However, if $\alpha_{i}$ is set lower than one, they direct their managers to pursue revenue generation at the expense of profits and if $\alpha_{i}$ is set greater than one they direct their managers to pursue cost minimization at the expense of profit generation. We let $\vec{\alpha}=\left(\alpha_{1}, \alpha_{2}, \ldots, \alpha_{n}\right)$ denote the profile of profit weights chosen by downstream owners.

We consider two scenarios depending on whether the upstream monopolist is able to precommit to a fixed input price. In the first scenario, we assume that price is difficult to change and communicate to customers. In this case, price commitments are credible. The order of moves is then as follows. The upstream monopolist moves first and sets the input price. After observing this price, downstream owners design their managerial compensation contracts simultaneously and independently. Obviously, the latter simply means setting the value of the profit weight $\alpha_{i}$. At the last stage of the game, managers compete in quantities so as to maximize their compensation, taking into account their target-based bonus and the input price.

\footnotetext{
${ }^{6}$ After delegation, the manager may not act in the owner's interest and engage in opportunistic practices and other self-serving behaviors. Managerial opportunism arises from two main sources (Eisenhardt, 1989) : (a) the objectives of the owner and the manager may conflict and (b) the owner may not be able to observe the behavior of the manager. The first is of little relevance in our context. Indeed, we assume that the manager is offered a performance-based bonus which reduces conflicts of interests and ensures that the manager will adhere to the owner's supply strategy. However, appropriate monitoring and governance mechanisms should be put in place in order to treat the second source of managerial opportunism. Indeed, unobservable behaviors may result in expropriation of the company funds (Shleifer \& Vishny, 1997). Common examples include the excessive consumption of perquisites such as luxurious offices and company jets. More broadly, managerial discretion may result in the allocation of company funds to the pursuit of pet projects or that of an irrational expansion of the firm.

${ }^{7}$ Consider a two-parts compensation contract $w_{i}=w_{i}^{F}+w_{i}^{V} F_{i}$ where $w_{i}^{F} \geq 0$ denotes the base salary and $w_{i}^{V}>0$ denotes the bonus rate that rewards performance as measured by $F_{i}$. Given this compensation contract, it is equivalent for manager $i$ to maximize the compensation $w_{i}$ or the target $F_{i}$. For more on this point see Kopel \& Pezzino (2018).
} 
Scenario 1: Price precommitment

\begin{tabular}{|c|c|c|}
\hline Stage 1 & Stage 2 & Stage 3 \\
\hline $\begin{array}{c}\text { The Upstream Firm } \\
\text { sets } k\end{array}$ & $\begin{array}{l}\text { Each Owner } i \\
\text { chooses } \alpha_{i}\end{array}$ & $\begin{array}{c}\text { Each Manager } i \\
\text { sets } y_{i}\end{array}$ \\
\hline
\end{tabular}

Scenario 2: Flexible pricing mechanism

$\begin{array}{ccc}\text { Stage } 1 & \text { Stage } 2 & \text { Stage } 3 \\ \begin{array}{c}\text { Each Owner } i \\ \text { chooses } \alpha_{i}\end{array} & \begin{array}{c}\text { The Upstream Firm } \\ \text { sets } k\end{array} & \text { Each Manager } i \\ \text { sets } y_{i}\end{array}$ Time

Fig. 1: Timing of the games: precommitment vs. flexible pricing

In the second scenario, we assume that prices are easy to change and communicate and the upstream monopolist is unable (or unwilling) to make a price precommitment. Without price commitment the upstream monopolist retains the opportunity to adjust the input price to changes in the behavior of downstream firms. The order of moves is then as follows. In the first stage of the game, Firm owners simultaneously and independently choose the compensation contracts that will be offered to hired managers (i.e., they set $\left.\alpha_{i}, i=1,2, \ldots, n\right)$. In the second stage, when the profile of managerial incentives $\vec{\alpha}$ is known and common knowledge, the upstream monopolist sets the input price $k$. Then, in the last stage, managers compete in quantities so as to maximize their compensation taking into account their target-based bonuses and the input price.

The difference between the timing of moves in the above two scenarios is illustrated in Figure 1. Both three stage games are solved by backward induction. Since the last stage is common to both games, it will be analyzed separately in the next section.

Throughout the paper, we make the following assumption:

Assumption 1. We assume that the efficiency of firms is sufficiently high, $1 \geq \varepsilon>\frac{\tau}{a+\tau}$, (or the price of energy is sufficiently low, $\frac{a \varepsilon}{(1-\varepsilon)}>\tau>0$ ) to ensure that all firms are active at the equilibrium.

\section{The managerial subgame}

At stage 3 , given $\vec{\alpha}$ and $k$, each manager $i$ simultaneously and independently chooses a quantity $y_{i}$ so as to maximize $F_{i}, i=1,2, \ldots, n$. Assuming an interior solution, the resulting system of first-order conditions is

$$
P(Y)+P^{\prime}(Y) y_{i}=\alpha_{i} A(k, \tau, \varepsilon), \quad i=1,2, \ldots, n .
$$

Obviously, these conditions repeat the standard provision that marginal revenue must equal the marginal cost of production. However, when the manager strikes the balance between marginal costs and revenue, he does not consider the firm's actual marginal cost of production $A(k, \tau, \varepsilon)$, but its depreciated (or inflated) value by the weight factor $\alpha_{i}$. By solving the i-th equation in (5) for $y_{i}$ we obtain:

$$
y_{i}=\frac{\alpha_{i} A(k, \tau, \varepsilon)-P(Y)}{P^{\prime}(Y)}, \quad i=1,2, \ldots, n .
$$

If $\alpha_{i}<1$, observe that the manager $i$ is induced to produce more than a profit-maximizing firm owner (for each output choice of its competitors). By choosing profit weights that 
are lower than one, owners induce their managers to be more aggressive on the output market.

Summing Equations (6) over $i$ results in:

$$
Y=\frac{A(k, \tau, \varepsilon) \sum_{i=1}^{n} \alpha_{i}}{P^{\prime}(Y)}-n \frac{P(Y)}{P^{\prime}(Y)},
$$

or, equivalently,

$$
Y P^{\prime}(Y)+n P(Y)=A(k, \tau, \varepsilon) \sum_{i=1}^{n} \alpha_{i} .
$$

This last equation implicitly defines the equilibrium industry output $Y^{\star}$ as a function of a weighted sum of the marginal costs of production incurred by the firms making up the industry. This result repeats the observation by Bergstrom \& Varian (1985a,b) that Cournot-Nash quantities depend solely on the sum of the firms' characteristics and, especially, are independent of how those characteristics are distributed. By substituting the inverse demand function $P(Y)=a-b Y$ into the fixed-point Equation (8) and solving for the equilibrium industry output level, we obtain:

$$
Y^{\star}=\frac{n a-A(k, \tau, \varepsilon) \sum_{i=1}^{n} \alpha_{i}}{b(n+1)} .
$$

Now, by plugging this quantity back into Firm $i$ 's (inclusive) reaction function (6), we obtain:

$$
y_{i}^{\star}=\frac{a+A(k, \tau, \varepsilon)\left(\sum_{i=1}^{n} \alpha_{i}-(n+1) \alpha_{i}\right)}{(n+1) b} .
$$

The implied equilibrium price is:

$$
P^{\star}:=P\left(Y^{\star}\right)=\frac{a+A(k, \tau, \varepsilon) \sum_{i=1}^{n} \alpha_{i}}{(n+1)} .
$$

\section{Price precommitment}

In this first scenario, the upstream monopolist precommits to an input price $k$. So, at the time when owners design their managers' compensation contracts, the pricing policy of the upstream monopolist is known and common knowledge. The timing of the game is depicted in Figure 1. At Stage 2, each owner simultaneously and independently chooses the incentives to provide to management (i.e., the profit weight $\alpha_{i}$ ). At stage 1 , the upstream supplier sets the input price $k$. Now, we resume the backward induction procedure starting with the design of managerial incentive contracts.

\subsection{Choice of managerial incentive contracts}

Each owner $i$ sets the profit weight $\alpha_{i}$ so as to maximize its profit taking the input price $k$ as given; i.e., owner $i$ solves

$$
\max _{\alpha_{i}} \pi_{i}=\left[P\left(Y^{\star}\right)-A(k, \tau, \varepsilon)\right] y_{i}^{\star}, \quad i=1,2, \ldots, n .
$$

Assuming an interior solution, we obtain the following system of $n$ first-order conditions for profit maximization:

$$
P^{\prime}\left(Y^{\star}\right) \frac{\partial Y^{\star}}{\partial \alpha_{i}} y_{i}^{\star}+\frac{\partial y_{i}^{\star}}{\partial \alpha_{i}}\left[P\left(Y^{\star}\right)-A(k, \tau, \varepsilon)\right]=0, \quad i=1,2, \ldots, n .
$$


The first term on the left-hand side corresponds to a gain in sales revenue linked to the price increase resulting from the reduction in total industry output. The second term corresponds to a profit loss linked to the reduction in firm $i$ 's supply. Conditions (13) indicate that managerial incentive contracts should be designed so as to balance these two countervailing effects.

From Equations (9) and (10), we obtain (See Appendix A.1):

$$
\left.\partial Y^{\star} / \partial \alpha_{i}=-A /(b(n+1)), \quad \partial y_{i}^{\star} / \partial \alpha_{i}=-n A /(b(n+1))\right) .
$$

Replacing in Equation (13), $P(Y), P^{\prime}(Y), \partial Y / \partial \alpha_{i}, \partial y_{i} / \partial \alpha_{i}$ and $y_{i}$ by their respective expressions, after straightforward calculations, we obtain:

$$
-(n-1)\left(a+A \sum_{i=1}^{n} \alpha_{i}\right)-(n+1) A\left(\alpha_{i}-n\right)=0, \quad i=1,2, \ldots, n .
$$

Solving each of the above equations, we find the expression of $\alpha_{i}$ as a function of $\sum_{i=1}^{n} \alpha_{i}$ :

$$
\alpha_{i}=n-\frac{(n-1)}{(n+1) A}\left(a+A \sum_{i=1}^{n} \alpha_{i}\right), \quad i=1,2, \ldots, n .
$$

Summing Equations (15) over $i=1,2, \ldots, n$, results in

$$
-(n-1) n a-\left(1+n^{2}\right) A \sum_{i=1}^{n} \alpha_{i}+n^{2}(n+1) A=0,
$$

from which we extract the expression of the weighted sum of managerial incentives

$$
\sum_{i=1}^{n} \alpha_{i}=\frac{n((n+1) n A-(n-1) a)}{\left(n^{2}+1\right) A} .
$$

Plugging this sum back into Equation (16) we find:

$$
\alpha_{i}^{c}=n-\frac{(n-1)}{\left(1+n^{2}\right) A}\left(a+n^{2} A\right), \quad i=1,2, \ldots, n .
$$

Plugging $\alpha_{i}^{c}$ back into Equations (9), (10) and (11) yields:

$$
P\left(Y^{c}\right)=\frac{a+n^{2} A}{\left(1+n^{2}\right)}, \quad Y^{c}=\frac{n^{2}(a-A)}{b\left(1+n^{2}\right)}, \quad y_{i}^{c}=\frac{n(a-A)}{b\left(1+n^{2}\right)}, \quad \pi_{i}^{c}=\frac{n(a-A)^{2}}{b\left(1+n^{2}\right)^{2}},
$$

$i=1,2, \ldots, n$. For the time being, let us assume that $k$ is given and fixed. Then, equilibrium values are presented in (20). As expected the solution is symmetric. Furthermore, the solution is admissible (i.e., prices and quantities are strictly positive) provided that $a>A$. From Equation (19), we obtain:

$$
\alpha_{i}^{c}=\alpha^{c}=1-\frac{(n-1)}{\left(1+n^{2}\right)}(a / A-1), \quad i=1,2, \ldots, n .
$$

Since admissibility implies $a>A$, it follows that $\left(\frac{a}{A}-1\right)>0$ and $\alpha^{c}<1$. In other words, equilibrium managerial compensation contracts provide that managers will be rewarded for deviations from profit maximization that favor sales revenue generation. Now, observe that $A(k, \tau, \varepsilon)>A(k, \tau, 1)=k$. Since $\partial \alpha^{c} / \partial A=a(n-1) /\left(A^{2}\left(1+n^{2}\right)\right)>0$, we find that the equilibrium profit weight $\alpha^{c}$ reaches a minimum when production generates no pollution (i.e., when $\varepsilon=1$ ):

$$
\left.\alpha^{c}\right|_{\varepsilon=1}=1-\frac{(n-1)}{\left(1+n^{2}\right)}(a / k-1) .
$$

This is the same expression as found by Claude (2018). Finally, still assuming that $k$ is given, we cannot exclude that $\alpha^{c}$ might be negative for some parameter values. Indeed, this could be the case for $a>(n(n+1) A) /(n-1)$. However, in the next section it is shown that $\alpha^{c}$ ranges in the interval $[0,1]$ when evaluated at the SPNE price $k^{c}$. 


\subsection{Monopoly pricing}

At stage 1, the upstream supplier sets the input price $k$ so as to maximize its profit; i.e., the monopolist solves

$$
\max _{k} \pi_{\mathrm{up}}^{c}=k n\left(y^{c} / \varepsilon\right) .
$$

Assuming an interior solution exists, the first-order condition for profit maximization is

$$
y^{c}+k\left(\frac{\partial y^{c}}{\partial k}\right)=0
$$

Solving the above equation for $k$, after straightforward computations, we obtain the following proposition.

Proposition 1. Suppose that the upstream monopolist precommits to a fixed input price. There exists a unique Subgame-Perfect Nash-Equilibrium. Equilibrium outcomes are, respectively,

$$
\begin{array}{llll}
k^{c} & =\frac{a \varepsilon-\tau(1-\varepsilon)}{2}, & \alpha^{c}=1-\frac{2(n-1) k^{c}}{\left(n^{2}+1\right)(a \varepsilon+\tau(1-\varepsilon))}, & y^{c}=\frac{n k^{c}}{b\left(n^{2}+1\right) \varepsilon}, \\
P^{c}=\frac{a \varepsilon\left(n^{2}+2\right)+n^{2}(\tau(1-\varepsilon))}{2\left(n^{2}+1\right) \varepsilon}, & \pi_{u p}^{c}=\frac{n^{2}\left(k^{c}\right)^{2}}{b\left(n^{2}+1\right) \varepsilon^{2}}, & \pi_{i}^{c}=\frac{n\left(k^{c}\right)^{2}}{b\left(n^{2}+1\right)^{2} \varepsilon^{2}} .
\end{array}
$$

Assumption 1 ensures that all the quantities given in the above proposition are non negative at the SPNE.

Remark 1. If $\varepsilon=1$, we obtain the managerial incentive as in Claude (2018),

$$
\left.\alpha^{c}\right|_{\varepsilon=1}=1-\frac{(n-1)}{\left(1+n^{2}\right)},
$$

and the same equilibrium values. Moreover, as $\varepsilon$ tends to $\tau /(a+\tau)$ the input price $k^{c}$ tends to zero, $\alpha^{c}$ tends to one and both upstream and downstream profits tends to zero.

We obtain the following comparative statics results:

$$
\frac{\partial k^{c}}{\partial \varepsilon}>0, \quad{\frac{\partial y^{c}}{\partial \varepsilon}}^{c}>0, \quad \frac{\partial \alpha^{c}}{\partial \varepsilon}<0, \quad \frac{\partial \pi_{i}^{c}}{\partial \varepsilon}>0, \quad \frac{\partial \pi_{\mathrm{up}}^{c}}{\partial \varepsilon}>0 .
$$

A reduction in pollution emissions or, equivalently in our model, an increase in the productivity of downstream firms, allows the upstream supplier to charge a higher input price $k$. Also, it provides firm owners with incentives to assign a lower weight to profit maximization in managerial compensation contracts. This lower weight encourages managers to adopt a more aggressive market behavior, which results in higher firm and industry output levels. As a result, both upstream and downstream profits rise. The exact inverse comparative static results obtains for changes in the tax rate $\tau$. This should come as no surprise given the inverse relationship between productivity and pollution emissions in our model.

Finally, we have $\alpha^{c} \in[0,1], \lim _{n \rightarrow+\infty} \alpha^{c}=1$, and $\frac{\partial \alpha^{c}}{\partial n}>0, \forall n>2$. We conclude that $\alpha^{c}$ is monotonically increasing in $n$ and converges to one as the number of downstream firms become arbitrarily large. Indeed, as the number of firms increases, the downstream market becomes more competitive implying that aggregate output rises and market price falls. This in turn leads to a reduction in marginal revenue that must be compensated by lower production volumes. Firm owners achieve the required production cut by assigning a lower weight $(1-\alpha)$ to sales in managerial compensation schemes. 


\section{Flexible pricing mechanism}

We now turn to the second scenario in which the order of firms' moves is reversed. At the time when the upstream monopolist sets the input price, it is assumed that the terms of managerial compensation contracts are known and common knowledge. The timing of the game is depicted in Figure 1. In stage 1, firm owners choose managerial incentives. In stage 2 , the upstream monopolist sets the input price. We now are in a position to resume the backward induction procedure starting with the resolution of the monopolist pricing problem.

\subsection{Input pricing}

In stage 2, the upstream monopolist sets the input price $k$ so as to maximize its profit: $\pi_{\text {up }}^{\star}=k \sum_{i=1}^{n} x_{i}^{\star}$. Recall that $y_{i}^{\star}=\varepsilon x_{i}^{\star}$ so that $x_{i}^{\star}=y_{i}^{\star} / \varepsilon^{\star}$. The decision problem of the upstream monopolist then writes as

$$
\max _{k} \pi_{\text {up }}^{\star}=k \sum_{i=1}^{n}\left(y_{i}^{\star} / \varepsilon^{\star}\right) .
$$

Assuming an interior solution exists, the optimal input price solves

$$
\sum_{i=1}^{n} y_{i}^{\star}+k\left[\frac{\partial}{\partial k}\left(\sum_{i=1}^{n} y_{i}^{\star}\right)\right]=0 .
$$

Replacing $y_{i}^{\star}$ by its value from (10) and solving for the optimal input price $k$ gives:

$$
k^{f}=\frac{n a \varepsilon-\tau(1-\varepsilon) \sum_{i=1}^{n} \alpha_{i}}{2 \sum_{i=1}^{n} \alpha_{i}} .
$$

As we shall see below, Assumption 1 ensures that $k^{f}$ is positive for the SPNE value of $\alpha_{i}$.

Note that

$$
\frac{\partial k^{f}}{\partial \alpha_{i}}=-\frac{n a \varepsilon}{2\left(\sum_{i=1}^{n} \alpha_{i}\right)^{2}}<0 .
$$

An increase in the weight downstream firms place on profits results in a decrease in the output price. Alternatively, a greater sale orientation causes a reduction in the input price. The economic intuition behind this result is straightforward. As the profit weight decreases, downstream managers are induced to behave more aggressively, producing more. The increase in input demand then explains the increase in input price

\subsection{Strategic delegation}

In stage 1 , each owner $i$ simultaneously and independently sets the profit weight $\alpha_{i}$ so as to maximize its profit. In other words, each owner $i$ solves the following problem

$$
\max _{\alpha_{i}} \pi_{i}^{f}=\left[P\left(Y^{f}\right)-A\left(k^{f}, \tau, \varepsilon\right)\right] y_{i}^{f}, \quad i=1,2, \ldots, n .
$$

First-order conditions for profit maximization are:

$$
\left(b \frac{\partial Y^{f}}{\partial \alpha_{i}}+\frac{1}{\varepsilon} \frac{\partial k^{f}}{\partial \alpha_{i}}\right)\left(P\left(Y^{f}\right)-\alpha_{i}^{f} A^{f}\right)+\left(A^{f}+\frac{\alpha_{i}^{f}}{\varepsilon} \frac{\partial k^{f}}{\partial \alpha_{i}}+b \frac{\partial Y^{f}}{\partial \alpha_{i}}\right)\left(P\left(Y^{f}\right)-A^{f}\right)=0,
$$

$i=1,2, \ldots, n$. Assuming a symmetric equilibrium, it is shown in Appendix A.2 that condition (30) reduces to

$$
g(\alpha):=\omega_{0}+\omega_{1} \alpha+\omega_{2} \alpha^{2}+\omega_{3} \alpha^{3}=0,
$$


where

$$
\begin{array}{ll}
\omega_{0}=a^{2} n^{2}(n+1) \varepsilon^{2}, & \omega_{2}=-n \tau(1-\varepsilon)(n(n+1)(a \varepsilon+\phi)-2 a \varepsilon), \\
\omega_{1}=-a\left(n^{2}-1\right) \varepsilon((n+2) \phi-n \tau(1-\epsilon)), & \omega_{3}=-n\left(n^{2}+1\right) \tau^{2}(\varepsilon-1)^{2},
\end{array}
$$

with $\phi=(a \varepsilon-\tau(1-\varepsilon))$.

The following proposition provides a characterization of equilibrium managerial incentives:

Proposition 2 (Equilibrium managerial incentives). Suppose that the upstream monopolist uses a flexible pricing mechanism. Then, there exists a unique symmetric SPNE characterized as follows.

1. The equilibrium profit weight takes values on the interval $(0,1]$;

2. If production generates no pollution emission then it is given by $\left.\alpha^{f}\right|_{\varepsilon=1}=\frac{n^{2}}{(n-1)(n+2)}$;

3. It is equal to one-implying pure profit maximization-in two cases:

(a) if the downstream market consists in a duopoly and production generates no pollution emission $(n=2, \varepsilon=1)$ and,

(b) in the limit case where downstream firms are so inefficient that they prefer to be inactive at the equilibrium $(\varepsilon=\tau /(a+\tau))$.

Proof. See Appendix A.3.

We remark that Points $3(a)$ and (b) in Proposition 2 include as special cases results by Claude (2018) which correspond to the model without pollution $(\varepsilon=1)$.

Assuming that $\alpha_{i}=\alpha^{f}$ for all $i=1,2, \ldots, n$, and plugging (28) into Equations (9)-(11) gives the following proposition:

Proposition 3. Equilibrium prices, quantities and profit levels are, respectively, given by

$$
\begin{gathered}
k^{f}=\frac{a \varepsilon-\tau(1-\varepsilon) \alpha^{f}}{2 \alpha^{f}}, \quad P^{f}=\frac{a \varepsilon(n+2)+n \tau(1-\varepsilon) \alpha^{f}}{2(n+1) \varepsilon}, \quad y^{f}=\frac{\alpha^{f} k^{f}}{b(n+1) \varepsilon}, \\
\pi_{u p}^{f}=\frac{n \alpha^{f}\left(k^{f}\right)^{2}}{b(n+1) \varepsilon^{2}}, \quad \pi^{f}=\frac{\alpha k^{f}\left((n+1)(a \epsilon+\tau(\epsilon-1))-k^{f}\left(\alpha^{f} n+n+1\right)\right)}{b(n+1)^{2} \epsilon^{2}} .
\end{gathered}
$$

Under Assumption 1, it is straightforward to show that the prices $k^{f}$ and $P^{f}$ and the quantities $y^{f}$ and $Y^{f}$ are strictly positive.

\section{Comparing equilibrium outcomes}

This section attempts to compare equilibrium outcomes depending on whether the upstream monopolist makes a price precommitment. A major difficulty in doing this is due to the complexity of the expression for $\alpha^{f}$. To begin with, we analyze how the decision to precommit alters managerial incentives in the downstream market. We are able to state the following proposition.

Proposition 4 (Comparison of managerial incentives). $\quad 1$. The equilibrium profit weight is lower when the upstream monopolist precommits to a fixed input price; i.e., $\alpha^{c}<\alpha^{f}$. 
2. As the number of downstream firms becomes arbitrarily large and irrespective of the pricing strategy adopted by the upstream monopolist, the equilibrium profit weight converges to 1 , implying that the behavior of managerial firms is eventually identical to that of profit-maximizing owner-managed firms; i.e., $\lim _{n \rightarrow \infty} \alpha^{h}=1, \quad h=c, f$.

Proof. See Appendix A.4.

The above proposition extends previous results by Claude (2018), that were established under the assumption that there is no pollution $(\varepsilon=1)$. It states that downstream owners offer compensation schemes that favor sale orientation over profit maximization if the upstream monopolist makes a price precommitment.

The intuition for this result can be traced back to the difference in the timing of moves between the two games that we consider. In the precommitment scenario, downstream owners set managerial incentives when the input price is known and has become common knowledge. Accordingly, in their decision-making process, they take the input price as fixed and given. By contrast, in the other scenario, the upstream monopolist adjusts the input price to the observed degree of competition on the downstream market (as proxied by managerial incentives). Then, downstream owners recognize that the price they pay for the input $x$ depends on the managerial incentives they give to their managers. Specifically, they know that a greater sale orientation (a lower value for $\alpha^{f}$ ) results in higher total downstream production, which, in turn, implies an increase in both input consumption and input price. The implied surge in production costs reduces the extent to which firm owners find it profitable to divert managers away from profit maximization; i.e. the value of $\left(1-\alpha^{f}\right)$.

Finally, as the number of firms rises, the downstream market becomes increasingly competitive so that the strategic value of delegation vanishes. Then, the behavior of managerial firms converges to that of profit-maximizing owner-managed firms.

Next, we compare equilibrium input prices between the two scenarios. When the downstream market structure is a duopoly and no environmental externality exists, Liao (2008; 2010) showed that the upstream monopolist sets the same equilibrium price irrespective of whether a price commitment was made. However, Claude (2018) proved that precommitment results in a lower input price if more than two firms operate on the downstream market. The following proposition extends this result to more general contexts in which production is polluting the environment:

Proposition 5 (Comparison of input prices). If the downstream industry (i) is a duopoly which generates no pollution emission or (ii) consists of infinitely many firms, then the upstream monopolist sets the same price in both scenarios (commitment or no commitment). Otherwise, precommitment results in a lower equilibrium input price.

Proof. From Equations (24) and (34), we obtain

$$
k^{c}-k^{f}=-\frac{a \varepsilon\left(1-\alpha^{f}\right)}{2 \alpha^{f}} \leq 0 .
$$

If $n=2$ and $\varepsilon=1$, then $\alpha^{f}=1$ and $k^{c}=k^{f}=a / 2$. Moreover, since $\alpha^{f}$ tends to 1 as the number of downstream firms becomes arbitrarily large, it follows that $\lim _{n \rightarrow \infty} k^{c}-k^{f}=$ 0 .

Turning to the comparison of production levels, we are able to prove the following proposition:

Proposition 6 (Comparison of downstream production levels). Downstream managers are encouraged to choose higher output levels if the upstream monopolist precommits to a fixed input price; i.e., $y^{c}-y^{f}>0$. Consequently, precommitment results in more pollution. 
Proof. We have

$$
\Delta y=y^{c}-y^{f}=\frac{a \varepsilon(n-1)-\left(n^{2}\left(1-\alpha^{f}\right)+n-\alpha^{f}\right)(1-\varepsilon) \tau}{2 b(n+1)\left(n^{2}+1\right) \varepsilon} .
$$

It is easy to see that $y^{c}-y^{f}>0$ if and only if $\alpha^{f}>\tilde{\alpha}$ where

$$
\tilde{\alpha}=1-\frac{(n-1)(a \varepsilon-\tau(1-\varepsilon))}{\left(n^{2}+1\right) \tau(1-\varepsilon)} .
$$

From Proposition 4, recall that $\alpha^{f}>\alpha^{c}$. A little algebra shows that $\alpha^{c}>\tilde{\alpha}$. Since $\alpha^{f}>\tilde{\alpha}$, it follows that $y^{c}>y^{f}$.

The intuition for this result can be understood by considering propositions 4 and 5 above. The former shows that, in the precommitment scenario, firm owners design compensation schemes so as to encourage a greater sale orientation (or, equivalently, a more aggressive market behavior). Under the same assumption, the latter proves that the upstream monopolist sets a lower input price. This, in turn, implies that the final good $y$ becomes less costly to produce. Then, the greater sale orientation combines with reduced production costs to encourage greater production and emissions of pollutant.

Next, we turn to the comparison of downstream and upstream profit levels. In the absence of environmental externalities, Claude (2018) showed the upstream monopolist is strictly better off when committing to a fixed input price. The exact opposite holds for downstream firms: if the upstream supplier engages in fixed price contracts, they earn lower profits.

These result might seem surprising at first sight, since the upstream monopolist charges a lower input price in the precommitment scenario. However, the basic intuition for this result is simple. If the upstream monopolist adopts a flexible pricing mechanism, downstream owners anticipate that a more aggressive market behavior will result in a higher input price. Then, each owner provides his management with lower sales incentives. In other words, each owner assigns a lower weight $(1-\alpha)$ to sales in managerial compensation schemes. This alleviates the problem of "over-competition" among firms arising from strategic delegation.

However, by waiving the right to adjust the input price to changes in managerial incentives, the upstream monopolist place firm owners back into their initial "prisoner's dilemma" situation. This strategic move creates the conditions for an overproduction that is unprofitable only for downstream owners. Indeed, precommitment makes the upstream monopolist better off since the surge in input consumption implied by overproduction more than compensates for the loss in revenue due to a reduced input price.

Unfortunately, if we relax the assumption that production causes no pollution, it becomes difficult to sign the difference between profits in the two scenarios for arbitrary parameter values. With that said, we are still able to shed some light on how profits compare and offer interesting insights on this issue. Let us recall that the admissible values of $\varepsilon$ lie in the range $\tau /(a+\tau)<\varepsilon<1$. By evaluating upstream and downstream profits at both extremities, we obtain the following proposition.

Proposition 7 (Comparison of profits). 1. If production causes no pollution, then the upstream monopolist is better off committing to a fixed input price:

$$
\left.\left(\pi_{u p}^{c}-\pi_{u p}^{f}\right)\right|_{\varepsilon=1}>0 .
$$

However, the precommittment decision of the upstream supplier is detrimental to downstream firms:

$$
\left.\left(\pi_{i}^{c}-\pi_{i}^{f}\right)\right|_{\varepsilon=1}<0
$$


2. For a sufficiently high level of emission per unit of the final good produced (or a sufficiently high environmental tax rate), downstream firms stop producing implying zero-profits for all:

$$
\left.\pi_{u p}^{c}\right|_{\varepsilon=\frac{\tau}{a+\tau}}=\left.\pi_{u p}^{f}\right|_{\varepsilon=\frac{\tau}{a+\tau}}=0=\left.\pi_{i}^{c}\right|_{\varepsilon=\frac{\tau}{a+\tau}}=\left.\pi_{i}^{f}\right|_{\varepsilon=\frac{\tau}{a+\tau}}, \quad i=1,2, \ldots, n .
$$

Proof. By plugging the value of $\varepsilon$ into the corresponding expressions.

We retrieve the same results as in Claude (2018). As a work around for the difficulty in signing differences in upstream and downstream profits, we ran numerical simulations. Despite extensive efforts, we found it impossible to find even one numerical example that is admissible and reverses the ranking between profits in Proposition 7 . If production generates few pollution emissions ( $\varepsilon$ is close to 1 ), numerical simulations confirm that the upstream firm is better-off when committing to a fixed input price (i.e., $\pi_{\text {up }}^{c}>\pi_{\text {up }}^{f}$ ). The opposite (i.e., $\pi_{\text {up }}^{c}<\pi_{\text {up }}^{f}$ ) was obtained only for so low values of $\varepsilon$ that downstream firms produce nothing. Finally, we confirmed numerically that downstream firms makes lower profits in the precommitment scenario. We conclude that previous results by Claude (2018) are robust to the introduction of pollution emissions from productive activities.

\section{Conclusion}

Recent advances in the strategic delegation literature emphasize that factor market imperfections reduce the incentive business owners have to manipulate the structure of incentives embedded in managerial compensation contracts so as to encourage managers to deviate from profit maximization. The purpose of this paper was to re-examine this issue by allowing for pollution emissions and related environmental tax payments.

Two scenarios were considered depending on whether the upstream monopolist supplies the intermediate product through fixed price contracts or relies on a flexible pricing scheme. The corresponding two games were solved by backward induction. In both cases, we proved the existence of a unique Subgame-Perfect Nash-Equilibrium (SPNE). Furthermore, we showed that the value of the equilibrium profit weight is restricted to the range from 0 to 1 . It was shown that equilibrium managerial incentives encourage pure profit maximization only in limit cases. Hence, non-profit managerial incentives are expected to be the norm rather than the exception. Furthermore, except in limit cases, the following results hold. A price precommitment results in a lower input price which encourages greater production of the final good and greater pollution emissions. Moreover, it makes the upstream supplier better off and downstream firms worse off. We conclude that upstream suppliers will choose to sign fixed price contracts with their customers.

This paper has limitations. For tractability reason, we assumed identical firms. Relaxing this assumption offers interesting challenges for future research. Furthermore, our analysis has focused exclusively on how precommitment alters managerial incentives in downstream market. Accordingly, the rate of environmental taxation was regarded as exogenous and the welfare consequences of precommitment were not investigated. Future research could examine the normative question of optimal environmental policy.

\section{A Appendices}

\section{A.1 Proof of Equation (14)}

Recall that Firm $i$ 's equilibrium output level is

$$
y_{i}^{\star}=\frac{\left(a+A(k, \tau, \varepsilon)\left(\sum_{i=1}^{n} \alpha_{i}-(n+1) \alpha_{i}\right)\right)}{(n+1) b},
$$


whereas that of Firm $j(j \neq i)$ is

$$
y_{j}^{\star}=\frac{\left(a+A(k, \tau, \varepsilon)\left(\sum_{i=1}^{n} \alpha_{i}-(n+1) \alpha_{j}\right)\right)}{(n+1) b} .
$$

Differentiating Equations (38) and (39) yields :

$$
\begin{aligned}
& \partial y_{i}^{\star} / \partial \alpha_{i}=\frac{A(1-(n+1))}{(n+1) b}=-\frac{n A}{(n+1) b}, \\
& \partial y_{j}^{\star} / \partial \alpha_{i}=\frac{A}{(n+1) b},
\end{aligned}
$$

and

$$
\sum_{j \neq i} \frac{\partial y_{j}}{\partial \alpha_{i}}=\frac{(n-1) A}{(n+1) b}
$$

Finally, we obtain :

$$
\begin{aligned}
\frac{\partial Y}{\partial \alpha_{i}} & =\sum_{j=1}^{n} \frac{\partial y_{j}}{\partial \alpha_{i}}=\sum_{j \neq i} \frac{\partial y_{j}}{\partial \alpha_{i}}+\frac{\partial y_{i}}{\partial \alpha_{i}}, \\
& =\frac{((n-1) A-n A)}{(n+1) b}=-\frac{A}{(n+1) b} .
\end{aligned}
$$

\section{A.2 Proof of Equation (31)}

Let us consider the first-order conditions for profit maximization which are given by :

$$
-\left(b \frac{\partial Y}{\partial \alpha_{i}}+\frac{1}{\varepsilon} \frac{\partial k}{\partial \alpha_{i}}\right)+\frac{\partial y_{i}}{\partial \alpha_{i}}(P(Y)-A)=0, \quad i=1,2, \ldots, n .
$$

From Equation (7), observe that

$$
y_{i}=\frac{a-\alpha_{i} A}{b}-Y,
$$

so that

$$
\frac{\partial y_{i}}{\partial \alpha_{i}}=-\left[\frac{1}{b}\left(A+\frac{\alpha_{i}}{\varepsilon} \frac{\partial k}{\partial \alpha_{i}}\right)+\frac{\partial Y}{\partial \alpha_{i}}\right] .
$$

Plugging $y_{i}$ and $\partial y_{i} / \partial \alpha_{i}$ back into (45), results in

$$
\left[b \frac{\partial Y}{\partial \alpha_{i}}+\frac{\partial A_{i}}{\partial \alpha_{i}}\right]\left(\frac{a-\alpha_{i} A}{b}-Y\right)+\left(\frac{1}{b}\left(A+\frac{\alpha_{i}}{\varepsilon} \frac{\partial k}{\partial \alpha_{i}}\right)+\frac{\partial Y}{\partial \alpha_{i}}\right)(P(Y)-A)=0 .
$$

Given that

$$
b\left(\frac{a-\alpha_{i} A}{b}-Y\right)=P(Y)-\alpha_{i} A,
$$

we obtain :

$$
\frac{1}{b}\left(b \frac{\partial Y}{\partial \alpha_{i}}+\frac{\partial A}{\partial \alpha_{i}}\right)\left(b\left(\frac{a-\alpha_{i} A}{b}-Y\right)\right)+\frac{1}{b}\left(\left(A+\frac{\alpha_{i}}{\varepsilon} \frac{\partial k}{\partial \alpha_{i}}\right)+b \frac{\partial Y}{\partial \alpha_{i}}\right)(P(Y)-A)=0,
$$

and, finally,

$$
\left(b \frac{\partial Y}{\partial \alpha_{i}}+\frac{1}{\varepsilon} \frac{\partial k}{\partial \alpha_{i}}\right)\left(P(Y)-\alpha_{i} A\right)+\left(\left(A+\frac{\alpha_{i}}{\varepsilon} \frac{\partial k}{\partial \alpha_{i}}\right)+b \frac{\partial Y}{\partial \alpha_{i}}\right)(P(Y)-A)=0 .
$$

Differentiating Equation (9) and (10) with respect to $\alpha_{i}$ yields

$$
\begin{aligned}
\frac{\partial Y}{\partial \alpha_{i}} & =-\frac{1}{b(n+1)}\left[A+\sum_{i} \frac{\alpha_{i}}{\epsilon} \frac{\partial k}{\partial \alpha_{i}}\right], \\
\frac{\partial y_{i}}{\partial \alpha_{i}} & =-\frac{1}{(n+1) b}\left(n A+(n+1)\left(\frac{\alpha_{i}}{\varepsilon} \frac{\partial k}{\partial \alpha_{i}}\right)-\sum_{i=1}^{n} \frac{\alpha_{i}}{\varepsilon} \frac{\partial k}{\partial \alpha_{i}}\right) .
\end{aligned}
$$


Plugging the following quantities

$$
\begin{aligned}
& \left.Y\right|_{\mathrm{sym}}=\frac{n(a-\alpha A)}{b(n+1)},\left.\quad \quad y_{i}\right|_{\mathrm{sym}}=\frac{(a-\alpha A)}{b(n+1)},\left.\quad k\right|_{\mathrm{sym}}=\frac{a \varepsilon-\tau(1-\varepsilon) \alpha}{2 \alpha}, \\
& \left.\frac{\partial Y}{\partial \alpha_{i}}\right|_{\mathrm{sym}}=-\frac{(a-\alpha A)}{b(n+1)},\left.\quad \frac{\partial y_{i}}{\partial \alpha_{i}}\right|_{\mathrm{sym}}=-\frac{(n a+\alpha A)}{b(n+1)},\left.\quad \frac{\partial k}{\partial \alpha_{i}}\right|_{\mathrm{sym}}=-\frac{a \varepsilon}{2 n \alpha^{2}} .
\end{aligned}
$$

into

$$
\left(b \frac{\partial Y}{\partial \alpha}+\frac{1}{\varepsilon} \frac{\partial k}{\partial \alpha}\right)(P(Y)-\alpha A)+\left(\left(A+\frac{\alpha}{\varepsilon} \frac{\partial k}{\partial \alpha}\right)+b \frac{\partial Y}{\partial \alpha}\right)(P(Y)-A)=0,
$$

yields the cubic equation (31).

\section{A.3 Proof of Proposition 2}

Let us consider the existence problem first. Let $\delta_{0}=\omega_{2}^{2}-3 \omega_{3} \omega_{1}$ and $\delta_{1}=2 \omega_{2}^{3}-$ $9 \omega_{3} \omega_{2} \omega_{1}+27 \omega_{3}^{2} \omega_{0}$. The discriminant of the third-degree polynomial $g(\alpha)$ can be expressed as $\Delta=-\left(\delta_{1}^{2}-4 \delta_{0}^{3}\right) /\left(27 \omega_{3}^{2}\right)$. Let us show that $\Delta<0$ so that Equation (31) has a unique real solution $\alpha^{f}$. To this end, it is convenient to express the discriminant as $\Delta=\eta \Gamma$ where

$$
\begin{aligned}
& \quad \eta=-4 a^{2} n(n+1) \tau^{2}(\epsilon-1)^{2} \epsilon^{2}<0 \text { and } \\
& \Gamma=\beta_{0}+\beta_{1} z+\beta_{2} z^{2}+\beta_{3} z^{3}+\beta_{4} z^{4} \quad \text { with } z=(\varepsilon-1)<0 \text { and } \\
& \beta_{0}=a^{4}\left(n^{2}+n-2\right)^{2}\left((n-1) n(n+2)^{2}-2\right) \epsilon^{4}, \\
& \beta_{1}=-2 a^{3}(n(n(n(n(n(n(3 n(n+2)-5)+5)+19)-31)-29)+16)+12) \tau \epsilon^{3}, \\
& \beta_{2}=a^{2}(n+1)(n(n(n(n(n(n(11 n-14)+31)-26)+13)+64)-16)-24) \tau^{2} \epsilon^{2}, \\
& \beta_{3}=-2 a(n+1)^{2}\left(2 n^{2}-1\right)\left(n^{2}(n(2 n-3)+2)-4\right) \tau^{3} \epsilon, \\
& \beta_{4}=n^{3}(n+1)^{3}\left(2 n^{2}-1\right) \tau^{4} .
\end{aligned}
$$

Examining Equations (59-63), we find that $\beta_{j}$ is positive (resp., negative) if $j$ is even (resp., odd), for all $j=0, \ldots, 4$. Since $z<0$, it follows that $\Gamma>0$ and thus $\Delta<0$.

We proceed by showing that $\alpha^{f}$ takes values on the interval $(0,1]$. Since $g(0)=\omega_{0}>0$, it follows that $\alpha^{f}$ cannot be equal to zero. Moreover, when $\frac{\tau}{a+\tau}<\varepsilon \leq 1$ we find that

$$
g(1)=\sum_{i=0}^{3} \omega_{i}=-(a \varepsilon-\tau(1-\varepsilon))(a(n-2)(n+1) \varepsilon+(n-1)(1-\varepsilon) n \tau)<0 .
$$

It follows that $g(\alpha)$ has a sign change on the interval $(0,1)$. Finally, if $\varepsilon=\tau /(a+\tau)$ recall that $(a \varepsilon-\tau(1-\varepsilon))=0$, so that $g(1)=0$. Hence, the unique real root $\alpha^{f}$ takes values on $(0,1]$.

\section{A.4 Proof of Proposition 4}

1. We proved that $g(\alpha)$ has a sign change on the interval $(0,1)$. Observe that $g(\alpha)>0$ implies that $\alpha<\alpha^{f}$. It follows that $\alpha^{c}<\alpha^{f}$ if $g\left(\alpha^{c}\right)>0$. Then, the proof reduces to showing that $g\left(\alpha^{c}\right)>0$.

Straightforward computations yield $g\left(\alpha^{c}\right)=\Phi h(t)$ where $\Phi=\frac{2 a \varepsilon(a \varepsilon-\tau(1-\varepsilon))}{\left(n^{2}+1\right)^{2}(a \varepsilon+\tau(1-\varepsilon))^{3}}>0$ and $h(t)=h_{0}+h_{1} \tau+h_{2} \tau^{2}+h_{3} \tau^{3}$, with

$$
\begin{array}{ll}
h_{0}=a^{3} \varepsilon^{3}(n+1)\left(n^{2}+1\right)\left(n^{2}-2 n+2\right)>0, & h_{1}=a^{2}(2 n+1)((n-1) n+2)^{2}(1-\varepsilon) \varepsilon^{2}>0, \\
h_{2}=a\left(n\left(n\left(n^{3}+2 n+4\right)+3\right)+2\right)(1-\varepsilon)^{2} \varepsilon>0, & h_{3}=n(n+1)^{2}(1-\varepsilon)^{3}>0 .
\end{array}
$$


Let $\Delta(h)$ denote the discriminant of $h(\tau)$. By direct computation, we find that

$$
\begin{aligned}
\Delta(h) & =-a^{6}(n-1)^{6} n(n+1)^{2}(\varepsilon-1)^{6} \varepsilon^{6} \Gamma, \quad \text { where } \\
\Gamma & =\left(8 n^{10}-n^{9}+6 n^{8}+59 n^{7}-48 n^{6}+156 n^{5}+64 n^{4}+28 n^{3}+96 n^{2}-68 n-64\right) .
\end{aligned}
$$

Since $\Gamma$ is strictly positive, it follows that $\Delta(h)<0$. Hence, the cubic equation $h(\tau)$ has a unique real solution. Since

$$
\left.h(\tau)\right|_{\tau=0}=a^{3}(n+1)\left(n^{2}+1\right)\left(n^{2}-2 n+2\right) \varepsilon^{3}>0,
$$

and $h^{\prime}(t)>0$, it follows that $h(\tau)>0$ for all $\tau \in\left[0, \frac{a \varepsilon}{1-\varepsilon}\right]$. Then $\Phi>0$ implies that $g\left(\alpha^{c}\right)>0$ so that $\alpha_{c}<\alpha_{f}$.

2. Since $\lim _{n \rightarrow \infty} \alpha^{c}(n)=1$ and $\alpha^{c}(n)<\alpha^{f}(n) \leq 1$, it follows that $\lim _{n \rightarrow \infty} \alpha^{f}(n)=1$.

\section{References}

Barcena-Ruiz, Juan Carlos, \& Garzon, Maria Begona. 2002. Environmental taxes and strategic delegation. Spanish Economic Review, 4(4), 301-310.

Bergstrom, Theodore C., \& Varian, Hal R. 1985a. Two remarks on Cournot equilibria. Economics Letters, 19(1), 5-8.

Bergstrom, Theodore C., \& Varian, Hal R. 1985b. When are Nash equilibria independent of the distribution of agents' characteristics? The Review of Economic Studies, 52(4), 715-718.

Breton, Michèle, Haurie, Alain, \& Georges, Zaccour. 1990. Methods in the Analysis of Multistage Commodity Markets. Pages 75 - 105 of: LEONDES, C.T. (ed), Advances in Large Scale Systems Dynamics and Control. Control and Dynamic Systems, vol. 36. Academic Press.

Claude, Denis. 2018. A reconsideration of the link between vertical externality and managerial incentives. Managerial and Decision Economics, 39(5), 526-534.

Claude, Denis, \& Zaccour, Georges. 2009. Investment in tourism market and reputation. Journal of Public Economic Theory, 11(5), 797-817.

Eisenhardt, Kathleen M. 1989. Agency Theory: An Assessment and Review. The Academy of Management Review, 14(1), 57-74.

Fershtman, Chaim, \& Judd, Kenneth L. 1987. Equilibrium incentives in oligopoly. The American Economic Review, 77(5), 927-940.

Fumas, Vicente Salas. 1992. Relative performance evaluation of management. International Journal of Industrial Organization, 10(3), $473-489$.

Jorgensen, S., \& Zaccour, G. 2004. Differential games in marketing. International Series in Quantitative Marketing, vol. 15. Boston, MA: Springer. Chap. Models of Maketing Channels.

Kopel, Michael, \& Pezzino, Mario. 2018. Strategic Delegation in Oligopoly. Chap. 24 of: Corchon, Luis, \& Marini, Marco (eds), Handbook of Game Theory and Industrial Organization. Edward Elgar.

Lambertini, Luca. 2017. An economic theory of managerial firms: strategic delegation in oligopoly. Routledge Studies in the Economics of Business and Industry. Routledge. 
Liao, Pei-Cheng. 2008. Input price contracts and strategic delegation with downstream duopoly. Academia Economic Papers, 36(4), 387-404.

Liao, Pei-Cheng. 2010. Discriminatory input pricing and strategic delegation. Managerial and Decision Economics, 31(4), 263-276.

Miller, Nolan, \& Pazgal, Amit. 2002. Relative performance as a strategic commitment mechanism. Managerial and Decision Economics, 23(2), 51-68.

Ngendakuriyo, Fabien, \& Zaccour, Georges. 2013. Fighting corruption: To precommit or not? Economics Letters, 120(2), 149 - 154 .

Pal, Rupayan. 2012. Delegation and Emission tax in a Differentiated Oligopoly. The Manchester School, 80(6), 650-670.

Park, Eun-Soo. 2002. Vertical externality and strategic delegation. Managerial and Decision Economics, 23(3), 137-141.

Sengul, Metin, Gimeno, Javier, \& Dial, Jay. 2012. Strategic delegation a review, theoretical integration, and research agenda. Journal of Management, 38(1), 375-414.

Shadbegian, R., \& Gray, W. 2003. What Determines Environmental Performance at Paper Mills? The Roles of Abatement Spending, Regulation, and Efficiency. Topics in Economic Analysis \& Policy, 3(1).

Shleifer, Andrei, \& Vishny, Robert W. 1997. A Survey of Corporate Governance. The Journal of Finance, 52(2), 737-783.

Sklivas, Steven D. 1987. The strategic choice of managerial incentives. The RAND Journal of Economics, 18(3), 452-458.

Vickers, John. 1985. Delegation and the Theory of the Firm. The Economic Journal, 95(Supplement: Conference Papers), 138-147.

Vural, Derya. 2018. Disclosure Practices by Family Firms: Evidence from Swedish Publicly Listed Firms. Accounting in Europe, 15(3), 347-373.

Wang, Leonard FS, \& Wang, Ya-Chin. 2010. Input pricing and market share delegation in a vertically related market: Is the timing order relevant? International Journal of the Economics of Business, 17(2), 207-221.

Wang, Zheng. 2015. Delegation and Vertical Externalities. Economics Bulletin, 35(2), $1128-1135$.

Zaccour, Georges. 1983. Calcul des pseudo-équilibres sur des réseaux représentant des marchés séquentiels. M.Sc. Thesis, H.E.C, Montreal.

Zaccour, Georges. 1987. Théorie des jeux et marchés énergétiques : marché européen du gaz naturel et échanges d'éléctricité. Ph.D. thesis, HEC Montréal. 